\title{
Horizontal Intra-Industry Trade in Korea: A Dynamic Panel Data Analysis
}

Author(s): Nguyen Khanh Doanh, Yoon Heo

Source: Journal of International Logistics and Trade 2018; 16(1):1-10

Published by: Jungseok Research Institute of International Logistics and Trade, Inha University

DOI: https://doi.org/10.24006/jilt.2018.16.1.001

The Journal of International Logistics and Trade is an official journal published by Jungseok Research Institute of International Logistics and Trade, Inha University, Korea. JILT welcomes manuscripts that advance the practice and science of logistics, trade, and other related fields.

Frequency: Quarterly (March, June, September, December)

Stable URL: https://www.ejilt.org

The Jungseok Research Institute of International Logistics and Trade is a specialized academic research institute representing Inha University and the Inha Foundation in Korea. The institute aims to become a representative institute in Northeast Asia in the research of logistics and trade.

Stable URL: https://jrieng.inha.ac.kr

(C) Copyright. Jungseok Research Institute of International Logistics and Trade.

This is an Open-Access article distributed under the terms of the Creative Commons Attribution NonCommercial License (http://creativecommons.org/licenses/by-nc/4.0/) which permits unrestricted noncommercial use, distribution, and reproduction in any medium, provided the original work is properly cited 


\title{
Journal of
}

\section{International Logistics and Trade}

\section{Horizontal Intra-Industry Trade in Korea: A Dynamic Panel Data Analysis}

\author{
Nguyen Khanh Doanh ${ }^{\mathrm{a}}$, Yoon $\mathrm{Heo}^{\mathrm{b} *}$ \\ a Thai Nguyen University, Thai Nguyen, Vietnam \\ ${ }^{\mathrm{b}}$ Graduate School of International Studies, Sogang University, Seoul, Korea
}

\begin{abstract}
ARTICLE INFO
Article history:

Received 01 July 2017

Accepted 12 March 2017

Keywords:

Intra-industry trade

Korea

System GMM

HIIT

Panel data

ABSTRACT

This study investigates the patterns and determinants of Korea's horizontal intra-industry trade by employing a dynamic panel data analysis. The main findings of the study are as follows. An increase in the market size of both trading partners is associated with a higher level of horizontal intra-industry trade. Dissimilar economic sizes and per capita incomes have a negative effect on trade in horizontally differentiated products. Geographical distance and trade imbalance serve as obstacles to horizontal intra-industry trade. These findings have policy implications for reconsidering the orientation of promoting trade. Inclusive economic growth in the region, taking advantage of neighboring nations and making efforts to reduce trade imbalances between trading economies, can accelerate further trade expansion through horizontal intra-industry trade.
\end{abstract}

\section{Introduction}

Over recent decades, global trade has shown consistent growth, most of which has been through intra-industry trade (IIT), namely the simultaneous import and export of goods within the same industry. Standard Heckscher-Ohlin theory of international trade, which is based on constant returns to scale, homogeneous products, and perfect competition, can only explain the observed phenomenon of inter-industry trade, which is the exchange of different goods. To account for IIT, theorists have developed models that extend imperfect competition to an open economy setting with assumptions of scale economies, product differentiation, and consumers' taste for variety (e.g., Helpman and Krugman, 1985).

Analysis of IIT provides a more comprehensive explanation when two-way trade is classified into two types: horizontal intra-industry trade (HIIT) and vertical intra-industry trade (VIIT). HIIT occurs among countries in terms of similar products with differentiated attributes, which is driven by the similarity in their factor endowments. By contrast, the dissimilarity in countries' factor endowments induces VIIT, which is reflected in the trade of products within the same industry but that belong to different stages of the production process (Grubel and Lloyd, 1975).

HIIT mainly takes place in the manufacturing sector among developed countries. The capability of differentiating products to satisfy customers' taste for variety enables those nations to develop trade by increasing IIT. As a country that follows an export-oriented strategy, Korea considers manufacturing exports to be an engine for trade growth.

From our preliminary investigation, it is noted that HIIT contributes a small share to overall trade in the manufacturing industry of Korea (In 1996-2012, average IIT indices ranged from 0.383 to 0.438 , whereas HIIT indices ranged from 0.244 to 0.300 ). As pointed out earlier, HIIT mostly happens among countries with similar factor endowments or, in other words, among countries at the same level of economic development. Our data show that Korea's large trading HIIT partners in manufacturing are indeed advanced economies or large neighboring countries such as Japan, the United States, and China. However, it seems that the wealthier these partners are, the smaller than expected the size of their trade in

\footnotetext{
* Corresponding author: Graduate School of International Studies, Sogang University, 35 Baekbeom-ro, Mapo-gu, Seoul 04107, Korea Email: hury@sogang.ac.kr
} 
horizontally differentiated products with Korea is. Crucial factors might be associated with this issue. Therefore, a comprehensive insight into the determinants of HIIT in Korea is significant for providing trade policy implications. Moreover, to our best knowledge, studies of two-way trade mostly investigate IIT (i.e., both HIIT and VIIT) or solely VIIT, whereas HIIT is rarely scrutinized.

Thus, this study aims to enrich the existing literature on trade in horizontally differentiated products. In particular, it examines the patterns and determinants of Korea's HIIT in the manufacturing industry by conducting a dynamic panel data analysis. It is guided by the following specific research objectives:

- To examine the patterns and trends of HIIT in Korea;

- To identify the determinants of HIIT in Korea's manufacturing sector; and

- To derive policy implications based on the empirical results of this study.

This study differs from previous empirical works in several key aspects. First, it operationalizes the theoretical distinction between HIIT and VIIT by using the latest methodology to decompose IIT into HIIT and VIIT (i.e., Kandogan, 2003a, 2003b). Second, to analyze the determinants of HIIT, this study uses a system generalized method of moment (GMM) model. This relatively new method allows us to overcome the problems of serial correlation, heteroskedasticity, and endogeneity for some explanatory variables through using a system of two equations, including first-differenced and levels equations. Finally, the analysis used in this study is based on the most recent and extensive data available (from 1996 to 2016 for 80 countries), having been constructed from the UN COMTRADE.

The rest of this paper is organized as follows. Section 2 provides a review of the literature on IIT. The theoretical framework and data analysis are given in Section 3. The empirical findings are discussed in Section 4 and Section 5 concludes and proposes policy implications.

\section{Literature review}

IIT has been the center of academic attention since Balassa (1966) recognized the growth in the simultaneous import and export of products in the same industry among EU member countries. Since then, an intensive array of literature has sought to theoretically and empirically explain the phenomenon.

Empirically, a great number of studies have attempted to identify the determinants of IIT. These studies can be classified into two groups: country-specific and industry-specific studies. Country-specific studies explain IIT through macroeconomic variables in each country (e.g., per capita income, distance, relative factor endowments, foreign direct investment, etc.), while industry-specific studies explain IIT as a function of industry-specific variables (e.g., scale economies, product differentiation, the firm concentration ratio, etc.). In seeking to empirically analyze the patterns and determinants of IIT, some studies have focused on country-specific determinants (e.g., Zhang et al., 2005; Zhang and Li, 2006), while others have focused on industry-specific factors (e.g., Vogiatzoglou, 2005; Algieri, 2007), with few studies focusing on both types of determinants (e.g., Bernhofen and Hafeez, 2001; Sichei et al., 2007).

Stone and Lee (1995) investigated the impact of five factors, namely tastes, scale economies, transaction costs, trade orientation, and trade imbalances, on IIT. Both static nonlinear least square and dynamic least square analyses were employed to compare IIT in the manufacturing and non-manufacturing economies. The estimation results imply that tastes, scale economies, and trade orientation are positively correlated with the share of IIT, whereas a contradictory relationship is found in the case of transaction costs and trade imbalances. Similar results were also found by Matthews (1998) for trade in Australia. However, in Stone and Lee (1995), the impacts differ when the analysis is carried out on the manufacturing and non-manufacturing countries separately. Then, the transaction costs proxied by the weighted distance between trade partners turn out to reveal the largest differences. Transaction costs exert negative impacts on IIT in manufacturing economies, while the impacts in non-manufacturing economies are significantly positive.

Recently, some studies have attempted to estimate the extent of HIIT and VIIT and analyze their determinants. The distinction between these two types of IIT is important because the theories regarding the driving forces of HIIT and VIIT lead to contradictory hypotheses (e.g., Greenaway et al., 1995). (In terms of horizontal models, two main approaches are found: monopolistic competition models, which are further subdivided into "love of variety" and "ideal variety" models, and models of oligopolistic competition. In terms of vertical models, there are two approaches: neo-Heckscher-Ohlin models and oligopoly models). Zhang et al. (2005) stated that IIT can be explained by consumption patterns, factor endowments, economic size, trade barriers, and the characteristics of international trade. Empirical evidence points out the same direction of the impact of economic size, distance, and trade openness on both HIIT and VIIT, whereas contradictory impacts are found in the case of differences in consumer patterns and factor endowments.

Zhang and Li (2006) included country-specific factors to investigate IIT, HIIT, and VIIT in manufacturing between China and East Asian countries. The estimation results of their fixed effects model show that market size is positively correlated with IIT and HIIT. Moreover, relative country size and relative factor endowments are found to be negatively related to IIT and HIIT. Further, the huge difference in relative factor endowments between countries might be more likely to induce inter-industry trade, which reduces HIIT. Trade orientation is included in the model to test for the relationship between IIT and the openness of the economy. The positive coefficient of trade orientation confirms that the 
more open the economy, the larger is the share of IIT, VIIT, and HIIT. Leitão (2012) employed system GMM analysis to account for IIT in the automobile industry in Portugal. The long-term effects of changes in IIT, VIIT, and HIIT were confirmed with a positive coefficient of the lagged value of intra-industry share.

In general, numerous efforts have been devoted to comprehensively explain the patterns and determinants of IIT in various countries. These studies are mostly based on data on the manufacturing sector, which clearly reflects the phenomenon of IIT. Various estimation methods (e.g., nonlinear least squares estimation of a logistic function, fixed effects model, factor analysis, etc.) have been applied to analyze the determinants of IIT. However, the GMM method, which takes into account econometric issues such as dynamic change, serial correlation, heteroskedasticity, and endogeneity, has rarely been used since the pioneering work of Faustino and Leitão (2007). Consequently, this study attempts to apply GMM analysis to investigate the patterns and determinants of Korea's HIIT using the most extensive dataset available.

\section{Theoretical framework}

\subsection{Measurement and decomposition of IIT}

Several measures of the degree of overlap between exports and imports have been put forward in the trade literature. Among them, Grubel-Lloyd (G-L) index has been widely used (Grubel and Lloyd, 1975). The index measures the share of IIT in industry $\mathrm{k}$ between country $i$ and country $j$. It is constructed as follows:

$$
I I T_{i j k t}=1-\frac{\left|X_{i j k t}-M_{i j k t}\right|}{X_{i j k t}+M_{i j k t}}
$$

where $X_{i j k t}$ is country $i$ 's exports of product $k$ to country $j$ in a specific year $t$, and $M_{i j k t}$ is country $i$ 's imports of product $k$ from country $j$ in a specific year $t$. The index ranges between zero (a complete inter-industry trade) and one (a complete intra-industry trade).

In order to measure the average IIT between country $i$ and country $j$ in all products, we use a trade weighted measure of IIT as follows:

$$
\overline{I I T_{i j t}}=\sum_{k=1}^{n} W_{i j k t}\left\{1-\frac{\left|X_{i j k t}-M_{i j k t}\right|}{X_{i j k t}+M_{i j k t}}\right\}
$$

where $W_{i j k t}=\left(X_{i j k t}+M_{i j k t}\right) / \sum_{i=1}^{n}\left(X_{i j k t}+M_{i j k t}\right)$ and $n$ is the number of industries at a chosen level of aggregation. The index measures the average IIT directly as a percentage of the export and import trade.

In order to decompose IIT into HIIT and VIIT we follow Kandogan's method (Kandogan, 2003a). The decomposition is undertaken based on the amount of export and import trade at two different levels of aggregation. The higher level of aggregation defines industries, whereas the lower level of aggregation defines products in each industry. Total IIT is calculated by finding the matched amount of exports and that of imports at two-digit level of SITC. HIIT is found by adding up the amount of matched trade in each product of an industry, specifically at four-digit level of SITC. The difference between IIT and HIIT is then defined VIIT. Finally, the unmatched portion of total trade in the industry would be inter-industry trade. Using Kandogan's method, the decomposition is carried out as follows:

$$
\begin{aligned}
& T T=\sum_{n} \sum_{i} X_{n i}+M_{n i} \\
& I I T=\sum_{n} 2 \min \left\{\sum_{i} X_{n i}, \sum_{i} M_{n i}\right\} \\
& I N T=T T-I T T \\
& H I I T=\sum_{n} \sum_{i} 2 \min \left\{X_{n i}, M_{n i}\right\} \\
& V I I T=I I T-H I I T
\end{aligned}
$$

where $n$ is the industry, $i$ is good $i$, and INT is inter-industry trade.

\subsection{Hypotheses}

Based on the theoretical foundation and empirical evidence, we have developed the following hypotheses regarding 
the determinants of HIIT:

Hypothesis 1: The higher the market size of both economies, the greater HIIT becomes.

An increase in the market size of both trading partners is considered to be associated with economies of scale, which in turn induces a higher level of IIT (Helpman and Krugman, 1985). Therefore, HIIT is expected to be positively correlated with the market size of both nations. Following Zhang and Li (2006), in this study, the average GDP (AGDP) of Korea (country $i$ ) and of each of its partners (country $j$ ) is used as a proxy for the market size of both economies.

$$
A G D P_{i j t}=\frac{1}{2}\left(G D P_{i t}+G D P_{j t}\right)
$$

where $G D P_{i t}$ is the GDP of Korea in a specific year $t$ and $G D P_{j t}$ is the GDP of the Korea's trading partner in a specific year $t$.

\section{Hypothesis 2: The greater the difference in the economic size of both economies, the lower HIIT becomes.}

Helpman and Krugman (1985) related the share of IIT to relative economic size. The gap in economic size between countries reflects the gap in their capability of producing differentiated products, which induces higher demand for products with different levels of quality. Thus, the more countries differ in relative economic size, the less likelihood there is for HIIT.

Following Balassa and Bauwens (1988), the difference in economic size (DGDP) between Korea and a given country is derived to reflect the standardized difference in size:

$$
D G D P_{i j t}=1+\frac{w \ln (w)+(1-w) \ln (1-w)}{\ln 2}
$$

where $w=G D P_{i t} /\left(G D P_{i t}+G D P_{j t}\right)$.

\section{Hypothesis 3: The greater the difference in per capita income, the lower HIIT becomes.}

Linder (1961) argued that countries at different levels of per capita income have different demand patterns. The greater the dissimilarity in their per capita income, the smaller the room is for trade in horizontally differentiated products. Consequently, we expect HIIT to be negatively correlated with the difference in per capita income (DPIN).

$$
D_{P I N} N_{i j t}=\left|\frac{G D P_{i t}}{P O P_{i t}}-\frac{G D P_{j t}}{P O P_{j t}}\right|
$$

where $P O P_{i t}$ is the population of Korea in a specific year $t$ and $P O P_{j t}$ is the population of the Korea's trading partner in a specific year $t$.

\section{Hypothesis 4: The greater the trade imbalance, the lower HIIT becomes.}

According to Grubel and Lloyd (1975), the size of any trade imbalance may reduce the value of two-way trade. Therefore, we introduce the variable of trade imbalance (TIMB) to control for any possible bias in estimating the determinants of HIIT (Clark and Stanley, 1999). HIIT is expected to be negatively related to TIMB.

Following Stone and Lee (1995) among others, TIMB is calculated as follows:

$$
T I M B_{i j t}=\frac{\left|X_{i j t}-M_{i j t}\right|}{\left(X_{i j t}+M_{i j t}\right)}
$$

where $X_{i t}$ is Korea's exports to country $j$ in a specific year $t$ and $M_{i j t}$ is Korea's imports from country $j$ in a specific year $t$.

\section{Hypothesis 5: The closer countries are geographically, the greater HIIT becomes.}

Geographical distance has long been considered to be an important determinant of IIT. Higher transportation costs reduce trade, including IIT and inter-industry trade (Sohn and Zhang, 2006). The reasons can be summarized as follows. 
Since a long distance increases information costs, the transaction costs of IIT rise when the countries are distant from each other. In addition, physical distance acts as a natural trade barrier, which deters the trade of closely substitutable products more than that of standardized products. Furthermore, in many cases, the production and demand patterns in a pair of neighboring countries are more similar than those in a pair of distant countries. Therefore, IIT covers a larger share of trade between proximate countries than it does between distant countries. In this study, we incorporate the distance between the capital city of Korea and that of each of its trading partners $\left(D I S T_{i j}\right)$ into the model. We expect $D I S T_{i j}$ to be negatively correlated with HIIT.

The above considerations give rise to the following model:

$$
\operatorname{HIIT}_{i j t}=f\left(A G D P_{i j t}, D G D P_{i j t}, D P I N_{i j t}, T I M B_{i j t}, D I S T_{i j}\right)
$$

where $H_{I I T} T_{i j t}$ is the HIIT between Korea and each of its trading partners in a specific year $t$.

In the model presented above, all the explanatory variables are in logs. Since the value of the $H_{I I T} T_{i j t}$ ranges from zero to unity, in order to perform the econometric analysis the dependent variable must be properly transformed. Following Hummels and Levinsohn (1995), this index is transformed by the following specification:

$$
\ln H I I T_{i j t}=\ln \left(\frac{H I I T_{i j t}}{1-H I I T_{i j t}}\right)
$$

\subsection{Estimation method}

In this study, we employ a dynamic modeling approach because the current value of HIIT depends on its past value. It means that the static specification of the original model is enhanced by incorporating a lagged dependent variable. This inclusion allows for the feedback of past shocks to current values of the dependent variable. Our dynamic panel data model is expressed as follows:

$$
H I I T_{i j t}=\alpha+\rho H I I T_{i j, t-1}+\beta X_{i j t}+v_{i j}+u_{i j t}
$$

where $v_{i j}$ is the fixed effect for each country pair and $u_{i j t}$ is the remaining part of the error term. All explanatory variables are assumed to be strictly exogenous and uncorrelated with $u_{i j t}$.

The inclusion of an autoregressive coefficient, however, makes classical linear estimators inconsistent and biased because $H I I T_{i j, t-I}$ would become correlated with $v_{i j}$. To overcome this problem, Arellano and Bond (1991) proposed a difference GMM. However, the lagged dependent variable, HIIT $T_{i j, t-1}$, is still correlated with $u_{i j, t-1}$. To overcome such correlation, Blundell and Bond (1998) elaborated a system GMM, which uses equation in first differences and equation in levels. The estimator provided better properties than all estimators in empirical researches.

Drawing on the works of Blundell and Bond (1998) and other empirical studies (Everaert and Pozzi; 2004 and Leitão, 2012), this study adopts the system GMM estimator in analyzing the determinants of Korea's HIIT. Our system GMM incorporates the original equation in levels into the system. The predetermined and endogenous variables in the level equation are instrumented with their lagged first differences. This approach allows us to solve the problems of serial correlation, heteroskedasticity, and endogeneity, permitting efficient estimates to be obtained. An individual-effects autoregressive panel data model with endogenous explanatory variables was considered. We perform a one-step system GMM estimator to estimate the equation.

Validity of the instruments. Performance is strongly dependent on the validity of the instruments. As a convention, a valid instrumental variable $z$ must meet the two following requirements:

$$
\begin{aligned}
& E|\in| z \mid=0 \text { (exogeneity) } \\
& \operatorname{cov}(z, x) \neq 0 \text { (relevance) }
\end{aligned}
$$

These two assumptions are tested by using the Sargan overidentifying restriction test and Arellano and Bond autocorrelation test. The assumption of the exogeneity of all instruments is tested by using the Sargan statistic, which assumes conditional homoskedasticity. This statistic is known to be relatively robust when a large number of instruments are used. However, it may not be consistent under heteroskedasticity. The Arellano and Bond autocorrelation test examines the differenced residuals to find the autocorrelation of the residuals in levels, which would be an indicator of weak, not exogenous instruments. 


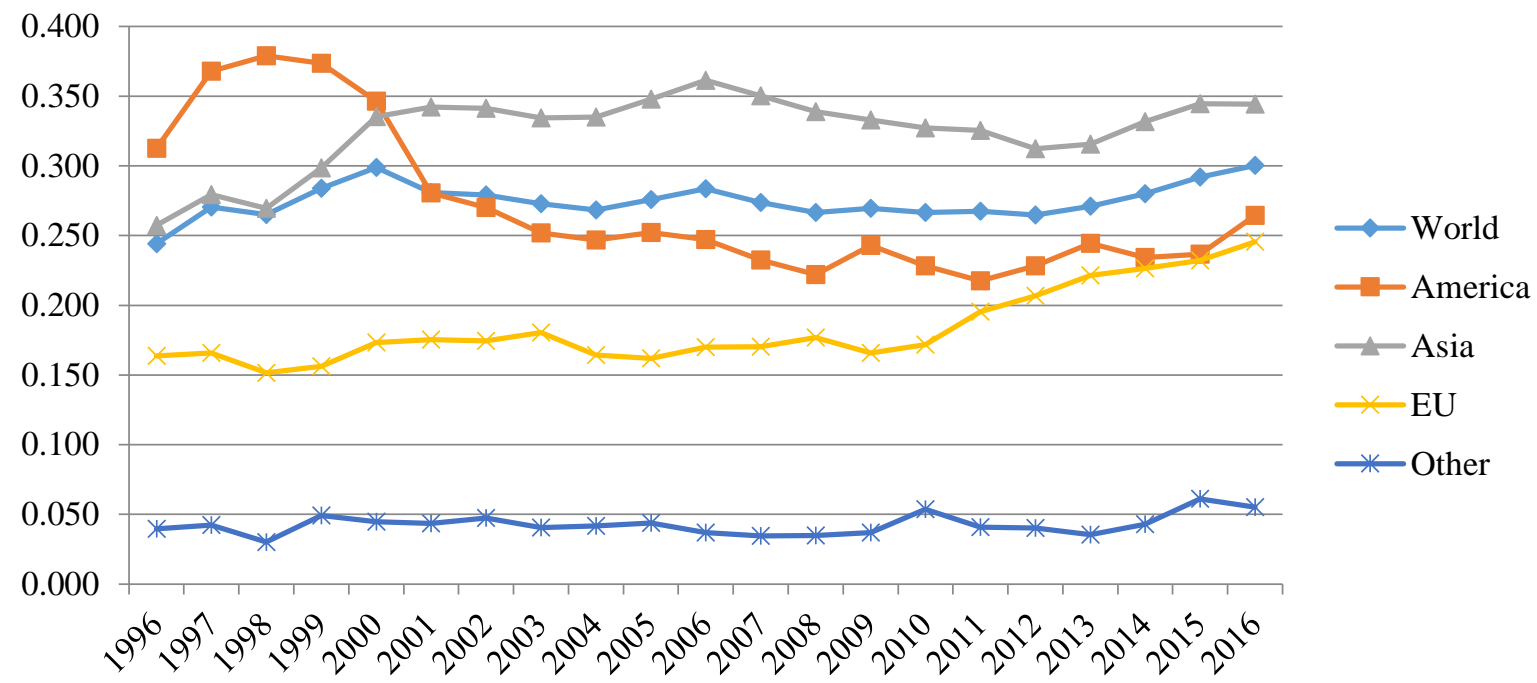

Figure 1. The trend of the average HIIT indices for 1996-2016 (Source: The authors' computation)

\subsection{Data}

In this study, we include 80 countries in our sample for 1996-2016 (A list of countries in the sample is displayed in Table A1). The dependent variable HIIT in the model is calculated by using bilateral export and import data for Korea and its 79 trading partners derived from UN COMTRADE. Korea's trading partners are chosen from different regions based on the availability of the data. Of the 79 trading partners, 16 nations are from Asia, 23 nations are from the EU, 18 nations are from America, and 22 nations are from the rest of the world. To calculate the HIIT, we follow the methodology of Kandogan (2003a, 2003b) who decomposes total IIT into HIIT and VIIT based on different levels of aggregation (including product level and sector level. The lower level of aggregation, or the product level, is used to calculate HIIT, whereas the sector level is used to calculate total IIT. The VIIT share is the remaining part of total IIT after subtracting HIIT. In this study, the SITC four-digit level is used to calculate HIIT, whereas the SITC 2-digit level is used to calculate total IIT). The variables are determined each year from 1996 to 2016. Country-income variables (GDP and per capita income) and population are collected from the IMF World Economic Outlook Database and Global Insight. Geographical distances between Korea and each of its trading partners are extracted from $<$ http://www.timeanddate.com/worldclock/distance.html>.

Table 1. Ten trading partners with the highest HIIT indices

\begin{tabular}{|c|c|c|c|c|c|c|c|}
\hline Countries & 1996-1998 & $1999-2001$ & $2002-2004$ & $2005-2007$ & $2008-2010$ & $2011-2013$ & 2014-2016 \\
\hline Singapore & 0.408 & 0.443 & 0.603 & 0.646 & 0.542 & 0.494 & 0.487 \\
\hline Japan & 0.379 & 0.412 & 0.422 & 0.408 & 0.386 & 0.411 & 0.435 \\
\hline China & 0.296 & 0.355 & 0.355 & 0.406 & 0.418 & 0.396 & 0.432 \\
\hline Malaysia & 0.268 & 0.550 & 0.414 & 0.419 & 0.367 & 0.339 & 0.399 \\
\hline Spain & 0.135 & 0.101 & 0.101 & 0.094 & 0.135 & 0.224 & 0.382 \\
\hline Thailand & 0.256 & 0.342 & 0.280 & 0.284 & 0.265 & 0.284 & 0.349 \\
\hline Germany & 0.188 & 0.217 & 0.273 & 0.294 & 0.304 & 0.360 & 0.344 \\
\hline Philippines & 0.282 & 0.467 & 0.584 & 0.501 & 0.476 & 0.367 & 0.333 \\
\hline Austria & 0.185 & 0.180 & 0.143 & 0.152 & 0.225 & 0.304 & 0.305 \\
\hline
\end{tabular}

Source: The author's computation

\section{Empirical results}

\subsection{Overview of the patterns of HIIT in Korea's manufacturing exports}

Figure 1 illustrates the trend of the average HIIT indices for 1996-2016. As can be seen from Figure 1, overall, there was a slight increase in the average HIIT indices of Korea's manufacturing industry. Starting from around 0.244 in 1996 , average HIIT fluctuated slightly until 2012, at which point it followed an upward trend. The highest average HIIT of Korea ends at 0.300 in 2016.

Specifically, Asia has made the largest contribution to the overall average HIIT of Korea. The average HIIT indices with Asian partners were markedly higher than the overall average HIIT indices, ranging from 0.257 in 1996 to 0.344 in 2016. However, most of the increase in Korea's overall average HIIT was attributed to EU countries. EU countries came 
second with average HIIT indices growing moderately from 0.164 in 1996 to 0.246 in 2016. Although the magnitude of Korea's HIIT with America is higher than that with EU, the index seems to exhibit a downward trend. Finally, Korea's HIIT with the rest of the world is minimal but relatively stable. A list of top ten countries displaying the highest value of HIIT with Korea is given in Table 1.

Table 1 reports the top ten partners with the highest HIIT indices. As the data revealed, the majority of large trading partners of Korea's manufacturing HIIT came from Asia and the EU. Over the period, Singapore maintained its dominant role with remarkably high HIIT indices (0.408 and 0.487 during the periods 1996-1998 and 2014-2016 respectively).

\subsection{Empirical findings}

A summary of statistics is presented in Table A2. DGDP $P_{i j t}$ and $D P I N_{i j t}$ appear to have little differences. However, and $T I M B_{i j t}, A G D P_{i j t}$ and $D I S T_{i j}$ show greater variations. Before performing the regression analysis, this study uses the Fisher test to check for unit roots in the important variables in the model, including $H_{I I T} T_{i j t}, A G D P_{i j t}, D G D P_{i j t}, D P I N_{i j t}$, and $T I M B_{i j t}$. The results of the Fisher unit root test are displayed in Table 2.

Table 2. Fisher test for unit root results

\begin{tabular}{ccc}
\hline Variables & z-value & Probability \\
\hline$H I I T_{i j t}$ & -17.962 & 0.000 \\
$A G D P_{i j t}$ & -18.477 & 0.000 \\
$D G D P_{i j t}$ & -13.059 & 0.000 \\
$D P I N_{i j t}$ & -21.269 & 0.000 \\
$T I M B_{i j t}$ & -14.336 & 0.000 \\
\hline
\end{tabular}

Source: Empirical results

As indicated in Table 2, the results of Fisher unit root test confirm that these variables have no unit roots or that they are stationary. The results of the SYS-GMM model on the determinants of Korea's HIIT are presented in Table 3. In order to check if our proposed SYS-GMM model is sensitive to the inclusion or omission of the independent variables, we carried out a sensitivity test by running three models. Model 1 starts with basic variables. After that, $T I M B_{i j t}$ and $D I S T_{i j}$ are added to the model 2 and model 3 respectively.

Table 3. Determinants of HIIT in Korea

\begin{tabular}{|c|c|c|c|}
\hline & Model 1 & Model 2 & Model 3 \\
\hline \multirow{2}{*}{$H I I T_{i j, t-1}$} & $0.244^{*}$ & $0.273^{*}$ & $0.253 * *$ \\
\hline & $(0.112)$ & $(0.107)$ & $(0.093)$ \\
\hline \multirow[t]{2}{*}{$A G D P_{i j t}$} & $0.923 * *$ & $0.748 * *$ & $0.668 * *$ \\
\hline & $(0.152)$ & $(0.124)$ & $(0.098)$ \\
\hline \multirow[t]{2}{*}{$D G D P_{i j t}$} & $-1.492 * *$ & $-1.148 * *$ & $-0.965 * *$ \\
\hline & $(0.264)$ & $(0.211)$ & $(0.168)$ \\
\hline \multirow[t]{2}{*}{$D P I N_{i j t}$} & $-0.795 * *$ & $-0.333 *$ & $-0.933 * *$ \\
\hline & $(0.216)$ & $(0.165)$ & (0.199) \\
\hline \multirow[t]{2}{*}{$T I M B_{i j t}$} & & $-0.532 * *$ & $-0.480 * *$ \\
\hline & & $(0.078)$ & $(0.061)$ \\
\hline \multirow[t]{2}{*}{$D I S T_{i j}$} & & & $-0.801 * *$ \\
\hline & & & $(0.116)$ \\
\hline \multirow[t]{2}{*}{ Constant } & $-8.013 * *$ & $-7.336 * *$ & 0.384 \\
\hline & $(1.281)$ & $(1.157)$ & $(0.617)$ \\
\hline $\begin{array}{l}\text { Number of } \\
\text { observations }\end{array}$ & 1580 & 1580 & 1580 \\
\hline
\end{tabular}

Note: Standard errors in parentheses; * significant at 0.05 level; ** significant at 0.01 level.

The sensitivity test showed that the signs and significance of the independent variables are pretty stable across three models. This indicates that our SYS-GMM model is not sensitive to the selection of the models. This proves the theoretical proposition that the SYS-GMM model is particularly powerful, especially in the case where important independent variables are omitted from the model.

Before interpreting the results, we undertook specification tests, whose results are given in Table 4. Again the specification tests are fairly consistent across three models. The $\operatorname{Ar}(2)$ test result confirms that there is no second-order serial correlation in the first-differenced residuals. The Sargan test result for overidentifying restrictions shows that the instruments used are valid.

As can be seen from Table 3, all the explanatory variables are statistically significant at the 1 percent level. The coefficient of $H I I T_{i j, t-l}$ is less than unity and has a positive sign, which indicates the significant effects of dynamic changes in HIIT in the long run. This result is consistent with the findings of Faustino and Leitão (2007) and Leitão (2012). 
Table 4. Specification tests

\begin{tabular}{lccc}
\hline & Model 1 & Model 2 & Model 3 \\
\hline Sargan test of overidentifying restriction & & 37.44 & 46.70 \\
$\quad$ Statistic & 34.78 & 0.273 & 0.567 \\
$\quad$ Probability & 0.383 & 1.83 & 1.87 \\
Arellano-Bond test for AR(2) in first differences & & 0.067 & 0.061 \\
$\quad$-test & 1.78 & 0.075 &
\end{tabular}

As expected, AGDP is positively correlated with HIIT. The result reconfirms the hypothesis that the greater market size of both trading partners induces a higher level of HIIT. There are two possible explanations for the relationship between the size of the economies and the level of HIIT. First, generally speaking larger economies are more likely to take advantage of economies of scale in production and trade. As a result, the range of differentiated goods produced locally will be greater. Second, countries with larger size often have higher demand for foreign differentiated products and thereby offer greater opportunities for trade in differentiated products.

The coefficient of $D G D P_{i j t}$ is statistically significant at the 1 percent level. In fact, its negative sign capture the hypothesis of the negative impact of $D G D P_{i j t}$ on $H I I T_{i j t}$. The result is in accordance with Helpman and Krugman (1985). Difference in market size exhibits differences in their abilities to produce differentiated products. As the economies become more similar, overlapping demand for differentiated products increases, providing better opportunity for trade in differentiated products.

A similar result occurs in the case of $D P I N_{i j t}$, whose coefficient is negative and statistically significant. This finding proves Linder's (1961) argument that countries with dissimilar per capita income exhibit a difference in the demand pattern and thus trade less in similar goods with differentiated attributes. In other words, countries with similar level of income per capita would have a greater degree of overlap in demand patterns and consumer tastes, which creates larger markets for the exchange of differentiated products of similar qualities. This allows trading partners to take advantage of scale economies of scale, which gives more scope for product differentiation to satisfy demand and thus lead to a higher share of HIIT.

As hypothesized, we expect that the closer the trading partners, the higher the level of HIIT. In fact, the estimate of geographical distance is negative and statistically significant at the 1 percent level, confirming the hypothesis of the negative impact on HIIT. This result is reflected in the fact that dominant trade partners of Korea's HIIT come from neighboring Asian countries. Similar findings can be found in many studies of HIIT (see Kandogan, 2003a; Leitão, 2012). Trade imbalance is proven to be a burden on $H I I T_{i j t}$ when its coefficients have a negative sign. This result is consistent with those of Stone and Lee (1995) and Matthews (1998).

\section{Policy implications and conclusion}

This study contributes to the body of the literature on the patterns and determinants of IIT. By applying panel data on Korea and 79 of its global trading partners, this study scrutinized Korea's HIIT in the manufacturing sector for 19962016. Kandogan's (2003a, 2003b) method of decomposing IIT was used to calculate the HIIT indices. Our findings show that Korea's HIIT indices followed an upward trend with some fluctuations over the period. Asian countries were Korea's largest trading partners of HIIT.

To investigate the determinants of $H I I T_{i j t}$, this study employed GMM-SYS analysis. The main findings can be summarized as follows. Firstly, the coefficient of $H I I T_{i j, t-1}$ is less than unity and has a positive sign. Thus, it can be concluded that dynamic changes in $H I I T_{i j t}$ exert long-term effects. Secondly, the coefficient of $A G D P_{i j t}$ is positive and statistically significant. In other words, a higher market size of both trading partners is associated with a higher level of $H_{I I T}$ ijt. Thirdly, a dissimilar economic size and per capita income exert a negative effect on trade in horizontally differentiated products. Lastly, the empirical findings support the hypothesis that geographical distance and trade imbalances serve as obstacles to $H I I T_{i j t}$.

From the analysis of the study, policy recommendations can be proposed to enhance the level of trade in similar products with different attributes among Korea and its trading partners. For example, inclusive economic growth in the region, taking advantage of neighboring countries and making efforts to reduce trade imbalances between Korea and its trading economies, can accelerate further trade expansion through $H I I T_{i j t}$.

Economies with dissimilar economic sizes and per capita incomes should reconsider their orientation of promoting trade. Trade in horizontally differentiated products is not a good choice for these nations. Another type of trade such as inter-industry trade or VIIT might be more suitable. In the case of Korea, additional efforts to nourish trade in horizontally differentiated goods with wealthy nations or those of more affluent social classes in China are recommended to bolster the country's HIIT. 
Owing to the detrimental effect of geographical distance, nations should fully utilize the close distance with their neighbors in order to boost HIIT. It is suggested that Korea should strengthen its trade relations with nearby Asian nations, especially Japan and China, making greater efforts to target the domestic consumption markets of these two economic giants. Another solution is to improve the quality of transportation system in order reduce the negative impact of the geographical distance.

Furthermore, the empirical findings warn of the need for more intensive trade liberalization such as the removal of tariff and non-tariff barriers among nations. Since China has a large economic size and is geographically close to Korea, the potentials for Korea's HIIT with China are high. Hence, efforts to upgrade the Korea - China FTA and attempts to lead the pluri-lateral trade agreements such as TiSA (Trade in Services Agreement) and EGA (Environmental Goods Agreement) should be accelerated to ensure gradual removal of tariff and non-tariff barriers. Such removal allows the two countries to boost their bilateral trade, which includes IIT.

This study made a great effort to examine the patterns and determinants of two-way trade. Owing to the availability of the data, only country-specific factors were considered. The effects of the determinants might have been explained more comprehensively if industry-specific factors such as scale economies, the firm concentration ratio, and firm-level technology had been added into the model as well. Further studies should aim to overcome this limitation.

\section{References}

Algieri, B., 2007. Trade specialization dynamics in Russia. Comparative Economic Studies 49, 232-258.

Arellano, M. and Bond, S.R., 1991. Some tests of specification for panel data: Monte Carlo evidence and an application to employment equations. Review of Economic Studies 58, 277-297.

Balassa, B., 1966. Tariff reductions and trade in manufacturers among the industrial countries. The American Economic Review 56, 466-473.

Balassa, B., Bauwens, L., 1988. The determinants of intra-European trade in manufactured goods. European Economic Review 32, $1421-1437$.

Bernhofen, D.M., Hafeez, Z., 2001. Oligopolistic competition and intra-industry trade: Evidence from the OECD. Australian Economic Papers 40, 77-90.

Blundell, R., Bond, S., 1998. Initial conditions and moment restrictions in dynamic panel data models. Journal of Econometrics 87 , 115-143.

Clark, D.P., Stanley, D.L., 1999. Determinants of intra-industry trade between developing countries and the United States. Journal of Economic Development 24, 79-92.

Everaert, G., Pozzi, L. 2004. Bootstrap Based Bias Correction for Homogeneous Dynamic Panels. Ghent University Working Paper No.2004/263.

Faustino, H.C., Leitão, N. C., 2007. Intra-industry trade: A static and dynamic panel data analysis. International Advances in Economic Research 13, 313-333.

Greenaway, D., Hine, R., Milner, C., 1995. Vertical and horizontal intra-industry trade: A cross industry analysis for the United Kingdom. The Economic Journal 105, 1505-1518.

Grubel, H.G., Lloyd, P.J. 1975. Intra-Industry Trade: The Theory and Measurement of International Trade in Differentiated Products, London: MacMillan.

Helpman, E., Krugman, P., 1985. Market Structure and Foreign Trade: Increasing Returns, Imperfect Competition, and the International Economy. Cambridge, MA: MIT Press.

Hummels, D., Levinsohn, J. 1995. Monopolistic competition and international trade: reconsidering the evidence. Quarterly Journal of Economics 110, 799-836.

Kandogan, Y., 2003a. Intra-industry trade of transition countries: Trends and determinants. Emerging Markets Review 4, $273-286$.

Kandogan, Y., 2003b. Reconsidering the adjustment costs of the Europe agreements. Applied Economics Letters 10, 63-68.

Leitão, 2012. GMM estimator: An application to intra industry trade. Journal of Applied Mathematics. Article Number: 857824, DOI: $10.1155 / 2012 / 857824$.

Linder, S., 1961. An Essay on Trade and Transformation, New York: Willey.

Matthews, K., 1998. Intra-industry trade: An Australian panel study. Journal of Economic Studies 25, 84-97.

Sichei et al., 2007. Determinants of South Africa-US intra-industry trade in services: A wild bootstrap dynamic panel data analysis. South African Journal of Economics 75, 521-539.

Sohn, C-H., Zhang, Z., 2006. How intra-industry trade is related to income difference and foreign direct investment in East Asia. Asian Economic Papers 4, 143-156.

Stone. J.A., Lee, H. 1995. Determinants of intra-industry trade: A longitudinal, Cross-Country Analysis, Weltwirtschaftliches Archiv. 131, 67-85.

Vogiatzoglou, K., 2005. Trends and determinants of intra-industry trade between Eastern European countries and Greece. Economic and Business Review 7, 81-99.

Zhang, J., Witteloostuijin, A.V., Zhou, C., 2005. Chinese bilateral intra-industry trade: A panel data study for 50 countries in the $1992-$ 2001 Period. Review of World Economics 141, 510-540.

Zhang, Z., Li, C. 2006. Country-specific factors and the pattern of intra-industry trade in China's manufacturing. Journal of International Development18, 1137-1149. 


\section{Appendix}

Table A1. List of countries in the sample

\begin{tabular}{cccccc}
\hline Order & Countries & Order & Countries & Order & Countries \\
\hline 1 & Argentina & 28 & Hong Kong SAR & 55 & Peru \\
2 & Australia & 29 & Hungary & 56 & Philippines \\
3 & Austria & 30 & Iceland & 57 & Poland \\
4 & Bangladesh & 31 & India & 58 & Portugal \\
5 & Belarus & 32 & Indonesia & 59 & Romania \\
6 & Bolivia & 33 & Ireland & 60 & Russia \\
7 & Brazil & 34 & Islamic Rep. of Iran & 61 & Saudi Arabia \\
8 & Bulgaria & 35 & Israel & 62 & Singapore \\
9 & Canada & 36 & Italy & 63 & Slovak Republic \\
10 & Chile & 37 & Jamaica & 64 & Slovenia \\
11 & China & 38 & Japan & 65 & South Africa \\
12 & Colombia & 39 & Jordan & 66 & Spain \\
13 & Croatia & 40 & Kazakhstan & 67 & Sri Lanka \\
14 & Cyprus & 41 & Kenya & 68 & Sweden \\
15 & Czech Republic & 42 & Korea & 69 & Switzerland \\
16 & Denmark & 43 & Kuwait & 70 & Thailand \\
17 & Dominican Rep. & 44 & Latvia & 71 & Tunisia \\
18 & Ecuador & 45 & Malaysia & 72 & Turkey \\
19 & Egypt & 46 & Mexico & 73 & Ukraine \\
20 & Estonia & 47 & Morocco & 74 & United Arab Emirates \\
21 & Finland & 48 & Nepal & 75 & United Kingdom \\
22 & France & 49 & Netherlands & 76 & United States \\
23 & Germany & 50 & Norway & 77 & Uruguay \\
24 & Ghana & 51 & Oman & 78 & Uzbekistan \\
25 & Greece & 52 & Pakistan & 79 & Venezuela \\
26 & Guatemala & 53 & Panama & 80 & Vietnam \\
27 & Honduras & 54 & Paraguay & & \\
\hline & & & &
\end{tabular}

Table A2. Summary of statistics

\begin{tabular}{|c|c|c|c|c|c|}
\hline Variable & Obs. & Mean & Std. Dev. & Min & Max \\
\hline$H I I T_{i j t}$ & 1659 & -3.484 & 2.012 & -10.494 & 0.612 \\
\hline$A G D P_{i j t}$ & 1659 & 6.665 & 0.576 & 5.722 & 9.246 \\
\hline$D G D P_{i j t}$ & 1659 & 0.418 & 0.283 & 0.000 & 0.936 \\
\hline$D P I N_{i j t}$ & 1659 & 0.173 & 0.197 & 0.000 & 0.771 \\
\hline$T I M B_{i j t}$ & 1659 & -0.704 & 0.877 & -6.422 & -0.000 \\
\hline$D I S T_{i j}$ & 1659 & 8.978 & 0.560 & 6.863 & 9.883 \\
\hline
\end{tabular}

Source: Empirical results 